\title{
Digital Transformation in Latin America - A Bibliometric Landscape of a Nascent Field
}

\author{
Julián David Cortés-Sánchez \\ Principal Professor \\ School of Management \\ Universidad del Rosario, Bogotá, Colombia \\ julian.cortess@urosario.edu.co
}

\begin{abstract}
This study presents the first bibliometric analysis of the subject of Digital Transformation (DT) in Latin America (LATAM). Social network analysis and key terms co-occurrence were implemented. It was found that the co-authorship network is geographically diverse and influenced by Brazil and Mexico, yet disconnected from the majority of LATAM countries. Research output and impact are increasing but still far from global dynamics and not yet permeated by the open access agenda. Finally, the most consolidated research topics associated with DT are "Industry 4.0", "smart manufacturing" and the "Internet of Things".
\end{abstract}

\section{Keywords}

Digital Transformation; Latin America; Bibliometrics.

\section{Introduction}

The International Telecommunication Union (ITU) defines Digital Transformation (DT) as what happens when innovation is applied to solve problems through the use of Information and Communication Technologies (ICTs) (ITU, 2018). These problems could be expressed by a set of stakeholders, such as entrepreneurs, the public sector, financiers, the private sector, entrepreneurial support networks and academics. The interest for DT by these stakeholders and the general public has been increasing substantially. Figure 1 displays the results for the search of two terms, namely "Digital Transformation" and "Industry 4.0" in Google Ngram Viewer, an online search engine that charts the frequencies of any word found in sources printed between 1500-2008.

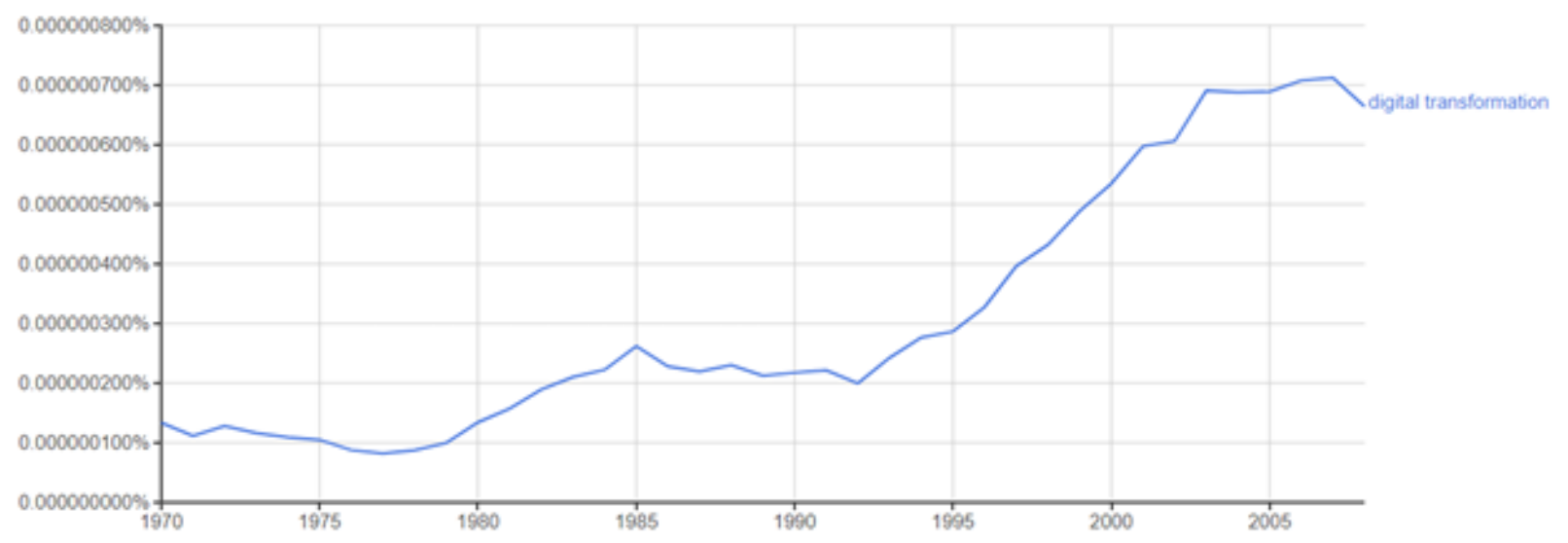


Figure 1. Search results for the terms "Digital Transformation" and "Industry 4.0" in Google Ngram Viewer. Source: Google Books Ngram Viewer.

The interest in DT has increased significantly also in academia. A Boolean search in Google Scholar using the terms "digital transformation", "transformación digital" (Spanish) or "transformação digital" (Portuguese), generated +17.000 results. The digital flood produced by the DT of academic publishing, requires a systemic appraisal to asses and consume this amount of content. Methods from bibliometrics allow identifying the most prolific authors and institutions, their impact, the most influential studies, intellectual communities, consolidated or nascent topics, among other factors (Zupic \& Čater, 2015). Nevertheless, bibliometric reports on DT, or related topics such as "Industry 4.0", are still in an embryonic state, even more in regions such as Latin America (LATAM).

The first bibliometric study on Industry 4.0 and DT was published until this year. Muhuri et al. (2019) argued that the field of Industry 4.0 is very young as the first article on the topic was published in 2012 . The article was entitled: "Inflation of industrial revolution" and was published by Ahrens, V. (2012). In this study: "Scientists, industry representatives and the federal government of Germany agreed that cyber-physical systems induce the 4th industrial revolution" (Ahrens, 2012, p. 30). Muhuri et al. (2019) also found that the most cited scholars are Hungan Kao at the Institute for Information Industry Taiwan and Jay Lee at the University of Cincinnati (United States) with 1251 and 5782 cites respectively (Scopus, 2019). The most cited study was conducted by Lee et al. (2015) with 782 citations. It was entitled: "A Cyber-Physical Systems architecture for Industry 4.0-based". Regarding journals' production, "IEEE Access" was highlighted in Web of Science (WoS) and "Procedia Manufacturing" in Scopus. The top-five most productive countries were Germany (547 documents indexed in Scopus), China (124), Italy (83), United Kingdom (82) and Spain (78). The landscape outlined by Muhuri et al. (2019) contributed to identifying crucial aspects of the research on Industry 4.0 and DT at a global scale. However, several questions emerged, mostly regarding LATAM.

First, Muhuri et al. (2019) did not elaborate on emerging intellectual communities (i.e., co-authorship networks) between neither countries nor institutions. Second, there was no information on journals' influence (e.g., journals' h-index). Third, when looking at the top ten most productive and influential institutions and countries, there was no mention to any LATAM entity. The research questions that emerged from these observations and guide this study, are: which are the most influential and productive countries, institutions and authors? Which is the publishers' market composition? Are there any intellectual communities? Which are the attributes of such communities? Which are the consolidated and emergent research topics?

Considering this research questions, the objective of this study is to produce a bibliometric outlook of the field of DT in LATAM. After this introduction, data sources and methods are presented. Then, the results are displayed and discussed. Finally, conclusions, limitations and future research are presented.

\section{Methodology}

\subsection{Data}

The bibliometric data was gathered from Scopus. Scopus is the largest bibliometric database of peer-reviewed literature. It contains more +5000 publishers, 22,800 serial titles, $+150,000$ books, 69 million items, 12 million author profiles, and 70,000 institutional profiles (Elsevier, 2017). The keywords used for the search were: "digital transformation", "transformación digital", and "transformaçáo digital". The search was limited to documents with authors with at least one affiliation to any institution from LATAM. The system found 40 documents. The majority of the documents were conference papers (65\%) published in 2018 (58\%). Forty 
percent of first authors were from Brazil followed by 20\% from Mexico. Citation data was also gathered from Google Scholar. Table I presents a description of the documents selected.

Table I Sample description

\begin{tabular}{|c|c|c|}
\hline \multicolumn{3}{|c|}{ Total documents $=40$} \\
\hline Year & Documents & Percentage \\
\hline 2004 & 1 & $3 \%$ \\
\hline 2013 & 1 & $3 \%$ \\
\hline 2016 & 6 & $15 \%$ \\
\hline 2017 & 5 & $13 \%$ \\
\hline 2018 & 23 & $58 \%$ \\
\hline 2019 & 4 & $10 \%$ \\
\hline \multicolumn{3}{|c|}{ Source } \\
\hline Conference paper & 26 & $65 \%$ \\
\hline Article & 15 & $38 \%$ \\
\hline Editorial & 1 & $3 \%$ \\
\hline Article in Press & 1 & $3 \%$ \\
\hline \multicolumn{3}{|c|}{ First author's country from LATAM } \\
\hline Brazil & 16 & $40 \%$ \\
\hline Mexico & 8 & $20 \%$ \\
\hline Ecuador & 2 & $5 \%$ \\
\hline Peru & 2 & $5 \%$ \\
\hline Argentina & 1 & $3 \%$ \\
\hline Costa Rica & 1 & $3 \%$ \\
\hline \multicolumn{3}{|c|}{ Subject area } \\
\hline Computer Science & 29 & $67 \%$ \\
\hline Engineering & 14 & $33 \%$ \\
\hline $\begin{array}{l}\text { Business, Management } \\
\text { Accounting }\end{array}$ & 8 & $19 \%$ \\
\hline Decision Sciences & 6 & $14 \%$ \\
\hline Mathematics & 5 & $12 \%$ \\
\hline Other & 11 & $26 \%$ \\
\hline
\end{tabular}

Source: author's based on Scopus (2018). Note: a same document can be categorized in several subject areas.

\subsection{Methods}

Social network analysis and key terms co-occurrence were implemented. Co-authorship networks are used to study scientific collaboration and can be reliably tracked by bibliometric methods (Glänzel \& Schubert, 2005). Networks were modeled in Gephi 0.9.2 and key terms co-occurrence visualization in VOSviewer 1.6.10. Both networks and nodes centrality properties were calculated in Gephi. Figure 1 present an example of the results by modeling Muhuri's et al. (2019) co-authorship and key terms data into networks. 


\subsubsection{Network analysis}

The network properties calculated for both country and institutional co-authorship networks were: mean degree, density, degree, closeness, betweenness and eigencentrality, given their general use in network analysis (Iacobucci et al., 2017). Equation 1 shows how to calculate the mean degree of a network.

$$
m d=\sum d / n(1)
$$

Source: Opsahl et al. (2010).

Where $n$ is the total of nodes (i.e., points or agents) in a network and $d$ is the degree (i.e., number of links a node has). The mean degree calculates how central on average nodes in a network are. Equation 2 shows how to calculate a network's density.

$$
\operatorname{den}=2 L / n(n-1)(2)
$$

Source: Scott (1988).

Where $L$ is the number of links and $n$ the number of nodes. The density is the proportion of links in a network relative to the total number of links possible: a density of 1 means the whole network is connected. Equation 3 shows how to calculate a node's degree.

$$
C_{D}\left(p_{k}\right)=\sum_{i=1}^{n} a\left(p_{i}, p_{k}\right)(3)
$$

Source: Opsahl et al. (2010).

Where $n$ is the number of nodes and $a\left(p_{i}, p_{k}\right)=1$ if and only if the node $i$ and $k$ are linked; $a\left(p_{i}, p_{k}\right)=0$ otherwise. The higher the degree, the more connected the node. Equation 4 shows how to calculate a node's closeness.

$$
C_{c}\left(p_{k}\right)=\sum_{i=1}^{n} d\left(p_{i}, p_{k}\right)^{-1}(4)
$$

Source: Opsahl et al. (2010).

Where $d\left(p_{i}, p_{k}\right)$ is the shorter path between nodes $p_{i} \mathrm{y} p_{k}$. The higher the closeness, the higher its centrality in the network. Equation 5 shows how to calculate a node's betweenness.

$$
C_{B}\left(p_{k}\right)=\sum_{i<j}^{n} \frac{g_{i j}\left(p_{k}\right)}{g_{i j}} ; i \neq j \neq k(5)
$$

Source: Opsahl et al. (2010).

Where $g_{i j}$ is the shorter path that links nodes $p_{i}$ and $g_{i j}\left(p_{k}\right)$ is the shorter path that links nodes $p_{i}$ and $p_{i} p_{k}$. The higher value, the higher its betweenness. Equation 6 shows how to calculate a node's eigencentrality.

$$
A x=\lambda x, \quad \lambda x_{i} \sum_{j=1}^{n} a_{i j} x_{j}, \quad i=1, \ldots, n(6)
$$

Source: Ruhnau (2000).

This equation describes the eigenvector centrality $x$ in two equivalent ways, as a matrix equation and a sum. The eigenvector centrality of a node is proportional to the sum of the eigenvector centrality of the nodes to which that node is linked to. $\Lambda$ is the vector value of $A$ (adjacency matrix) and $n$ the number of nodes. An eigenvector value of 1 corresponds to the node with the highest quality of links in the network regardless of its degree. 


\section{Results}

Results are presented in three sections: first, co-authorship network analysis by countries and institutions, and authors' networks visualization; then, the publishing market, production and citation outlook; finally, the key terms co-occurrence network.

\subsection{Co-authorship network analysis by countries and institutions, and authors' networks visualization}

\subsubsection{Countries}

Table II shows the network's centrality properties of the ten most relevant countries. The mean degree was 1.2 and the density 0.07 . Brazil and Mexico were the most connected and influential nodes.

Table II Countries' co-authorship network centrality properties

\begin{tabular}{rlrrrr}
\hline & Country & Degree & Closeness & Betweenness & Eigen.centrality \\
\hline 1 & Brazil & 8 & 0,0 & 0,0 & 1,0 \\
2 & Mexico & 6 & 0,7 & 16,0 & 0,8 \\
3 Netherlands & 2 & 0,5 & 0,0 & 0,5 \\
4 United States & 2 & 0,5 & 0,0 & 0,5 \\
5 & France & 2 & 1,0 & 0,0 & 0,4 \\
6 & Italy & 2 & 1,0 & 0,0 & 0,4 \\
7 India & 3 & 0,8 & 10,0 & 0,4 \\
8 Portugal & 2 & 1,0 & 0,0 & 0,4 \\
9 & Australia & 2 & 0,0 & 0,0 & 0,3 \\
10 & Chile & 3 & 1,0 & 2,0 & 0,3 \\
\hline
\end{tabular}

Source: calculations in Gephi based on Scopus (2019).

Figure 2 shows the countries' co-authorship network. The network was composed by 17 nodes (i.e., countries) and 21 links (i.e., co-authorships). Entities from Chile (green) have published more documents with entities from Oceania (yellow) and Asia (blue) than from Europe (red). Brazil, on the other hand, has published almost exclusively with entities from Europe and North America. Along with Chile, Mexico is an interesting case of diversity as it has published with entities from North America, Europe, Asia and Oceania. Only four out of 20 countries from LATA are coauthoring with entities from either the region or external. 


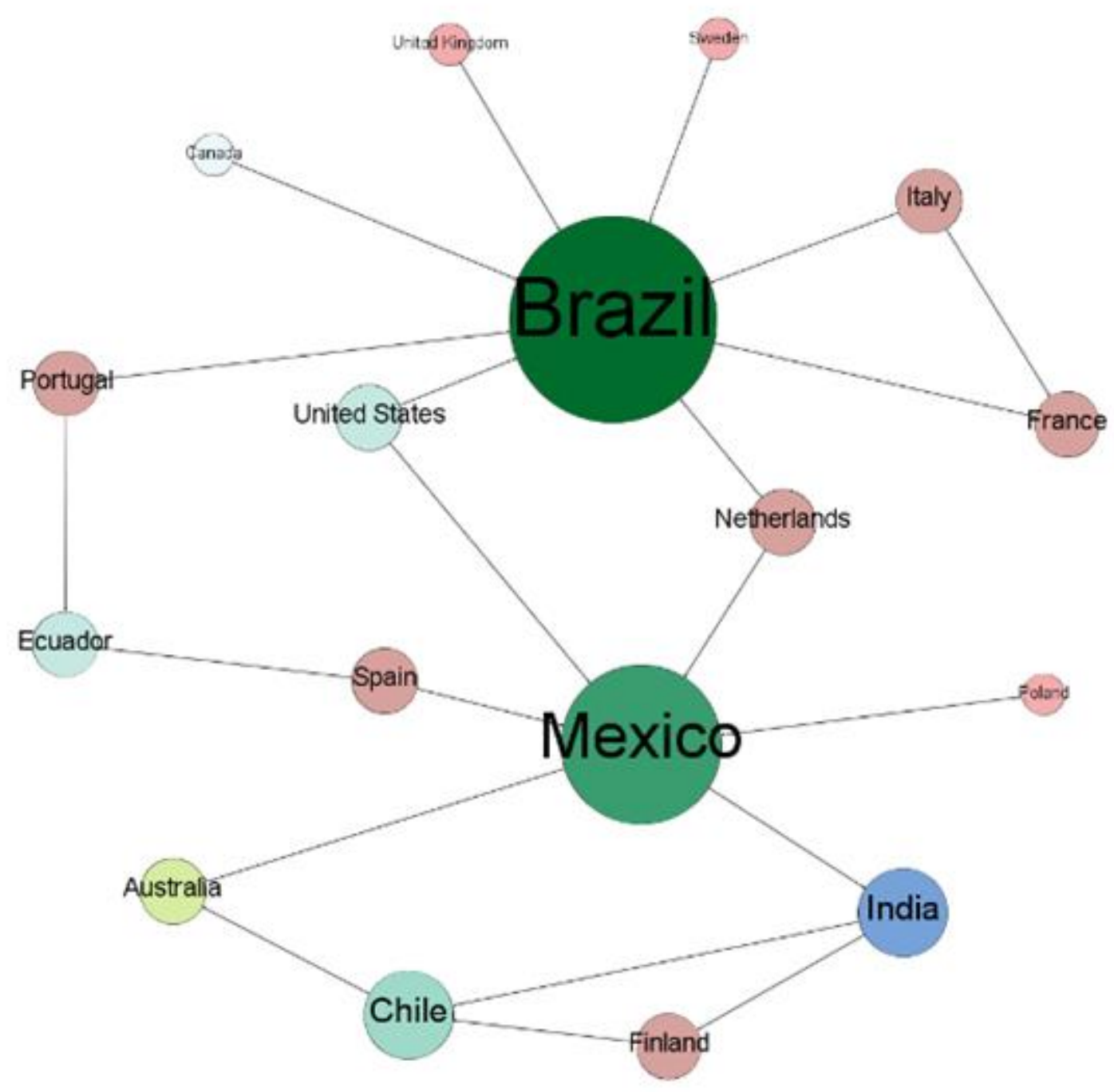

Figure 2 Countries' co-authorship network. Source: author's elaboration in Gephi based on Scopus (2019).

\subsubsection{Institutions}

Table III displays the network's centrality properties of the ten most influential institutions. The mean degree was 1.7 and the density 0.039. Eighty percent of the institutions have degree 1. Wageningen University (Netherlands), Federal University of Mato Grosso (Brazil), Joint Institute for VLBI ERIC (Netherlands), Cardiff University (United Kingdom) and Pantanal Research Centre (Brazil) were the most connected and influential nodes.

Table III Institutions' co-authorship network centrality properties

\begin{tabular}{|c|c|c|c|c|c|}
\hline & Institution & $\begin{array}{c}\text { Degre } \\
\mathrm{e}\end{array}$ & Closeness & Betweenness & $\begin{array}{c}\text { Eigen.centralit } \\
\mathrm{y}\end{array}$ \\
\hline 1 & Wageningen University and Research & 4 & 1,0 & 0,0 & 1,0 \\
\hline 2 & Federal University of Mato Grosso & 4 & 1,0 & 0,0 & 1,0 \\
\hline
\end{tabular}




\begin{tabular}{|c|c|c|c|c|}
\hline 3 & Joint Institute for VLBI ERIC & 1,0 & 0,0 & 1,0 \\
\hline 4 & Cardiff University & 1,0 & 0,0 & 1,0 \\
\hline 5 & Pantanal Research Centre & 1,0 & 0,0 & 1,0 \\
\hline 6 & InstitutoTecnologico de Monterrey & 1,0 & 5,0 & 0,1 \\
\hline 7 & $\begin{array}{l}\text { Federal University of Rio Grande do } \\
\text { Sul }\end{array}$ & 1,0 & 5,0 & 0,1 \\
\hline 8 & Universidade Federal de Sao Carlos & 0,7 & 0,0 & 0,1 \\
\hline 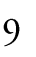 & Politecnico di Milano & 0,7 & 0,0 & 0,1 \\
\hline 1 & Ultrech University & 0,7 & 0,0 & 0,1 \\
\hline 0 & & & & \\
\hline
\end{tabular}

Source: calculations in Gephi based on Scopus (2019).

Figure 3 shows the institutions co-authorship network. The network was composed of 46 nodes (i.e., institutions) and 40 links (i.e., co-authorships). Most of the institutions have co-authored with just one institution. It is a fractionated network, confirmed by the almost non-existent betweenness property. Only four institutions have published more than one document: Universidad Complutense de Madrid (Spain) with the Universidad Estatal de Sonora (Mexico); and Vector Consulting Services (Brazil) with the Brazilian Development Bank (Brazil). The larger communities identified orbited around the Wagenin University, Federal University of Rio Grande do Sul (Brazil) and Tecnológico de Monterrey (Mexico).

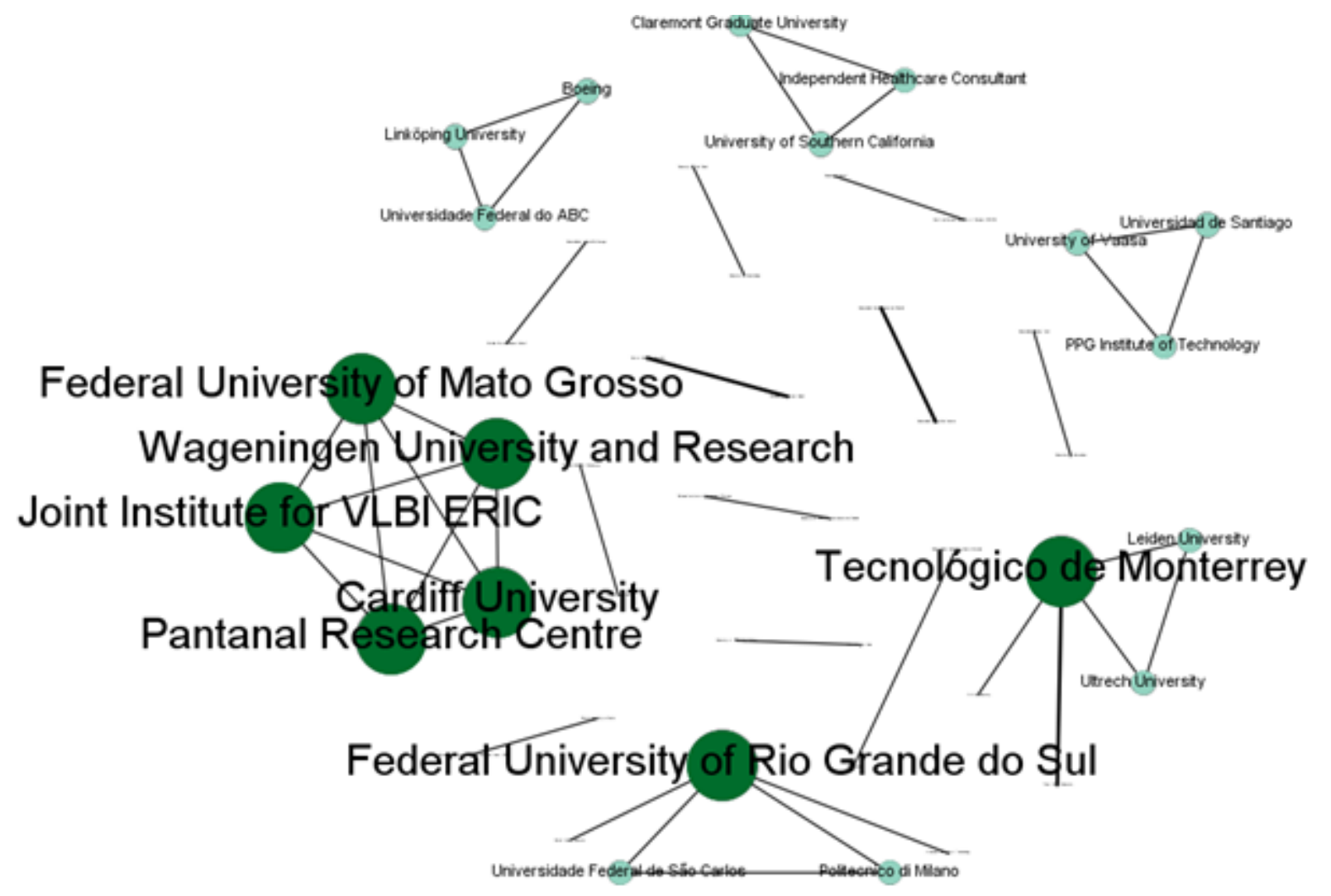

Figure 3 Institutions' co-authorship network. Source: author's elaboration in Gephi based on Scopus (2019). 


\subsubsection{Authors}

Figure 4 presents the co-authors' network. Networks where Romero, D. from Instituto Tecnológico de Monterrey and Gastaud Maçada A.C. from Federal University of Rio Grande do Sul were involved, highlighted from the rest in terms of the number and diversity of researchers integrated into those clusters (Figure 5).

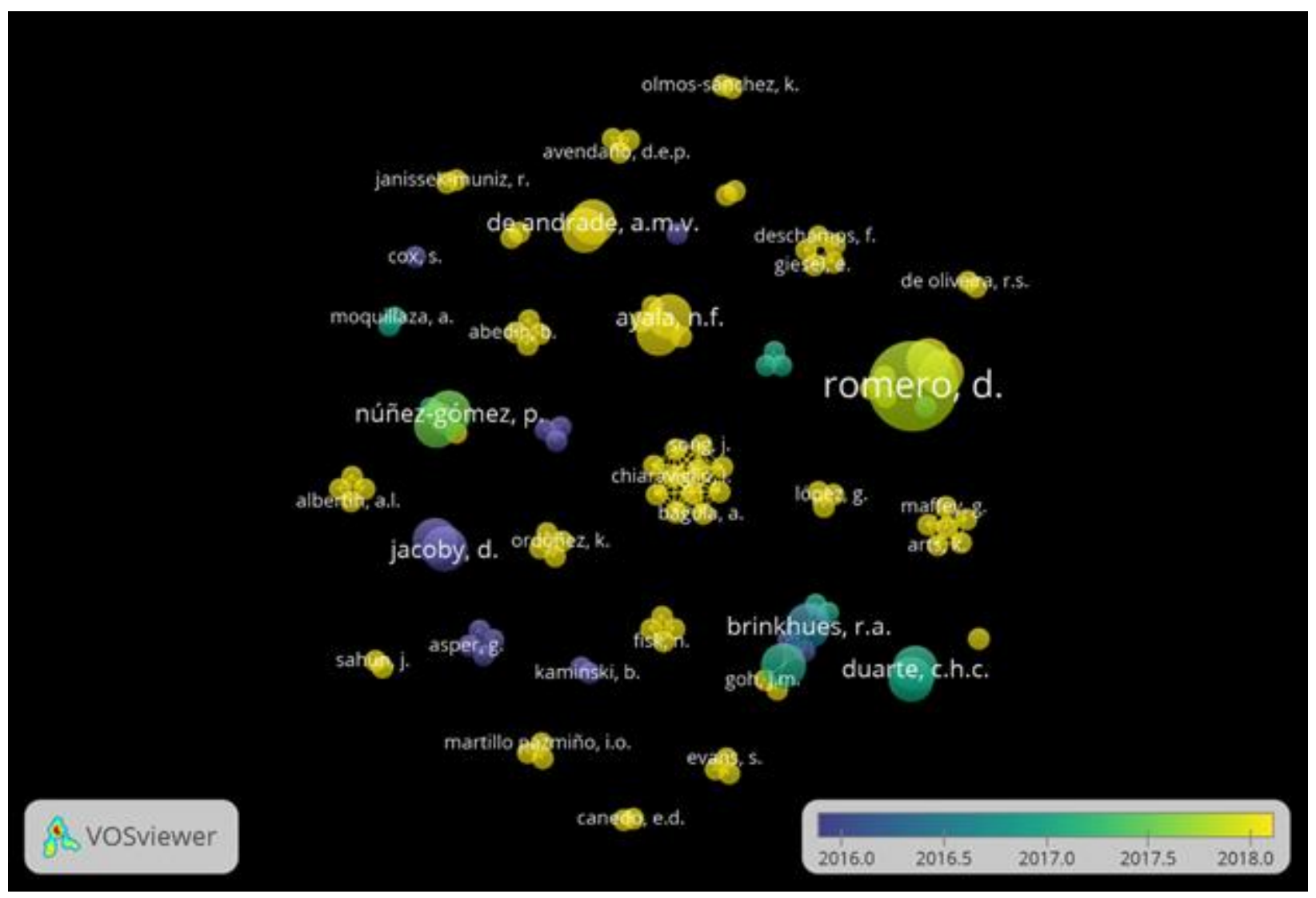

Figure 4 Co-authorship network. Source: VOSviewer based on Scopus (2019). 

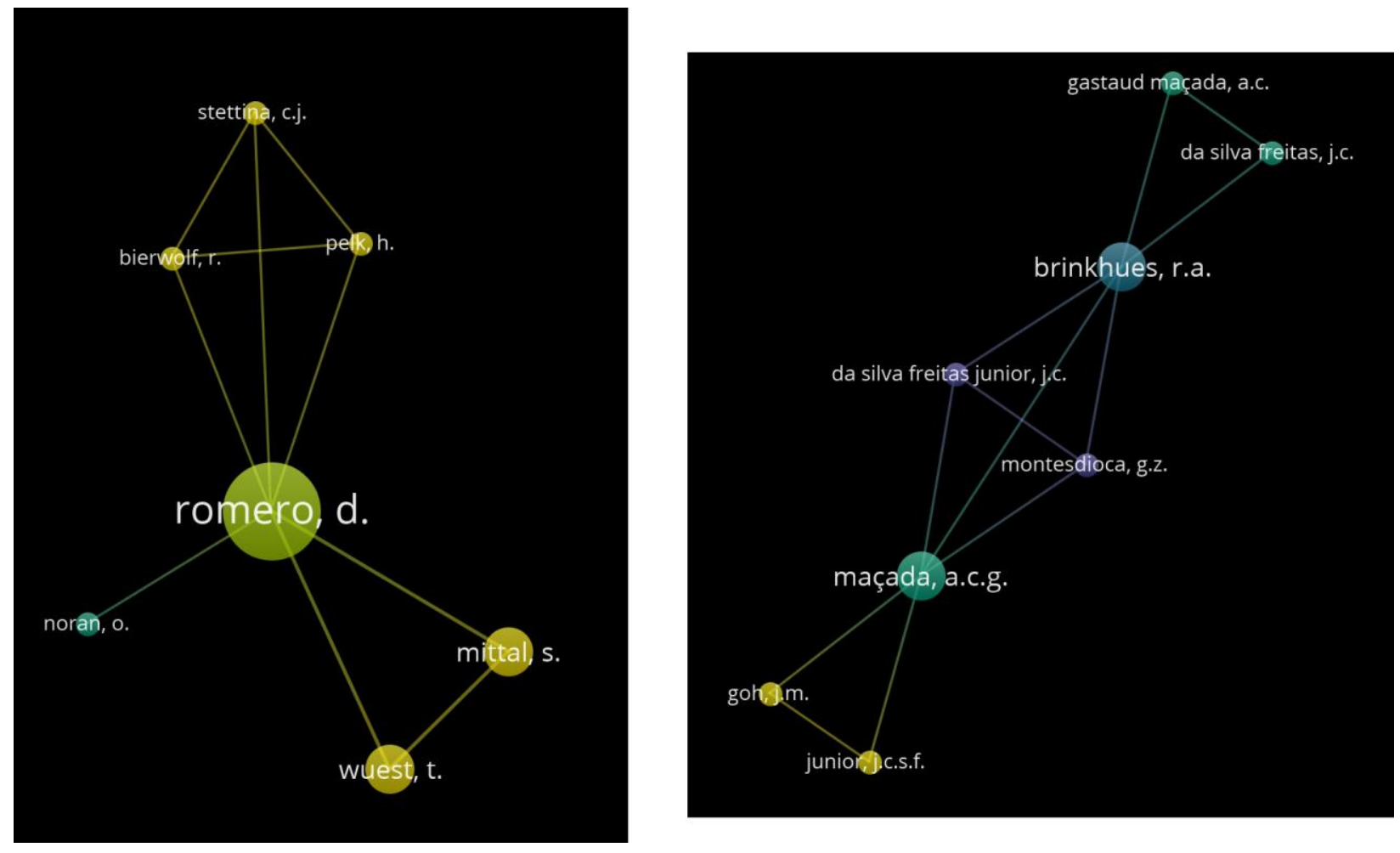

Figure 5 The two most numerous authors' communities. Source: VOSviewer based on Scopus (2019).

\subsection{The publishing market, production and citation outlook}

The number of publishing entities was eighteen, although $66 \%$ of the documents were published by only five entities, namely: Americas Conference on Information Systems (AMCIS); the Institute of Electrical and Electronics Engineers (IEEE); Springer; Elsevier; and the Cutter Information Corp. (CIC) (Figure 6). 


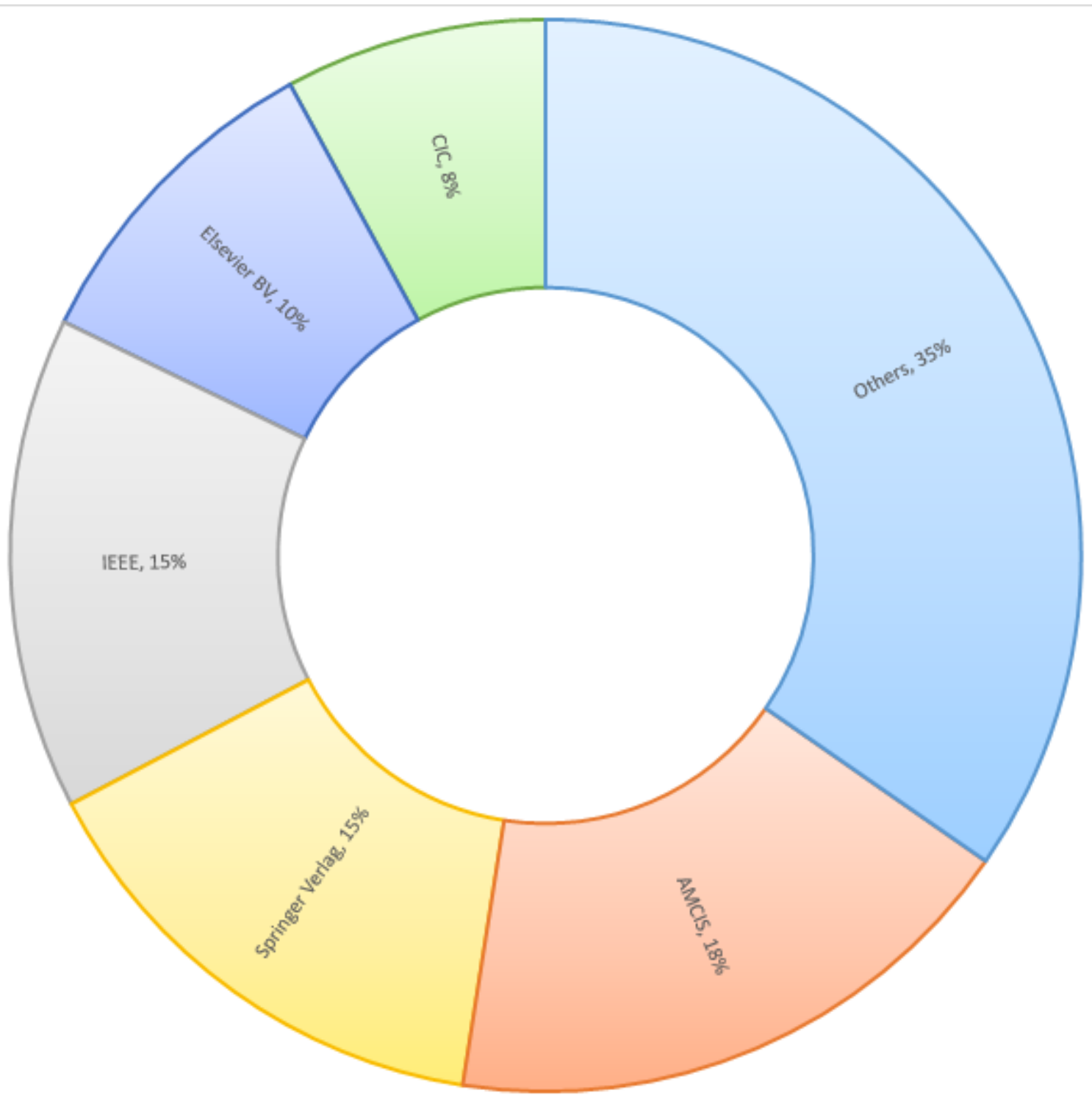

Figure 6 Publishing market. Source: Author's, based on Scopus (2019) and SCImago (2019).

Table IV presents the top-ten most cited documents. The mean number of authors per paper was 2.7. The mean citation in Scopus was 2.3. In Google Scholar was 5. In comparative terms, Google Scholar finds nearly all WoS and Scopus citations, in addition, citations in Google Scholar are from non-journal citations (i.e., theses, books, conference papers, and unpublished materials)(Martín-Martín, et al., 2018). Twenty-six documents $(65 \%)$ have no citations. The mean journal's h-index was 25.7. As a reminder, an entity has index $h$ if $h$ its $N p$ papers have at least $h$ citations each and the other $(N p-h)$ papers have $\leq h$ citations each (Hirsch, 2005). For instance, yours truly has an h-index 4 in Google Scholar, which means that my four most cited papers have at least four citations.

The most cited paper in Scopus (6 cites) was authored by Stokalski and Kaminski (2016) affiliated to Cutter Consortium, entitled: "All the world's a sound stage: The digital transformation journey in the era of Hollywood economics". It was published in the journal Cutter IT Journal with an h-index 13. Conversely, the most cited paper in Google Scholar (20 cites) was authored by Gray, P. et al. (2013) affiliated to Claremont 
Graduate University (United States), entitled: "Realizing strategic value through center-edge digital transformation in consumer-centric industries". It was published in the journal MIS Quarterly Executive with an h-index 25. The first published document was authored by Saint-Nom and Jacoby (2004). It was entitled: "Switched capacitors: A bridge between analog and digital SP" and published in the IEEE International Symposium on Circuits and Systems. 
Table IV Top ten most cited documents

\begin{tabular}{|c|c|c|c|c|c|c|c|c|c|c|}
\hline & First author & $\begin{array}{c}\text { First author's } \\
\text { affiliations }\end{array}$ & $\begin{array}{c}\text { First } \\
\text { author's } \\
\text { country }\end{array}$ & $\begin{array}{c}\# \\
\text { Authors }\end{array}$ & Year & Title & Source title & $\begin{array}{l}\text { Source h- } \\
\text { index }\end{array}$ & $\begin{array}{c}\text { Cites } \\
\text { (Scopus) }\end{array}$ & Cites (GS) \\
\hline 1 & $\begin{array}{l}\text { Sganzerla } \\
\text { C. }\end{array}$ & Accenture & Brazil & 3 & 2016 & $\begin{array}{l}\text { Disruptive Innovation in } \\
\text { Digital Mining }\end{array}$ & Procedia Engineering & 40 & 6 & 8 \\
\hline 2 & $\begin{array}{l}\text { Álvarez- } \\
\text { Flores E.P. }\end{array}$ & $\begin{array}{l}\text { Universidad } \\
\text { Estatal de } \\
\text { Sonora }\end{array}$ & Mexico & 3 & 2017 & $\begin{array}{l}\text { E-skills acquisition and } \\
\text { deficiencies at the university } \\
\text { in the context of the digital } \\
\text { economy }\end{array}$ & $\begin{array}{l}\text { Revista Latina de } \\
\text { Comunicacion Social }\end{array}$ & 8 & 5 & 1 \\
\hline 3 & Gray P. & $\begin{array}{l}\text { Claremont } \\
\text { Graduate } \\
\text { University }\end{array}$ & $\begin{array}{l}\text { United } \\
\text { States }\end{array}$ & 4 & 2013 & $\begin{array}{l}\text { Realizing strategic value } \\
\text { through center-edge digital } \\
\text { transformation in consumer- } \\
\text { centric industries }\end{array}$ & $\begin{array}{l}\text { MIS } \\
\text { Executive }\end{array}$ & 25 & 5 & 20 \\
\hline 4 & Ebert C. & $\begin{array}{l}\text { Vector } \\
\text { Consulting } \\
\text { Services }\end{array}$ & $\begin{array}{l}\text { United } \\
\text { States }\end{array}$ & 2 & 2016 & $\begin{array}{lr}\text { Requirements } & \text { Engineering } \\
\text { for the } & \text { Digital } \\
\text { Transformation: } & \text { Industry } \\
\text { Panel } & \end{array}$ & $\begin{array}{lr}\text { Proceedings } & -2016 \\
\text { IEEE } & 24 t h \\
\text { International } & \\
\text { Requirements } & \\
\text { Engineering } & \\
\text { Conference, RE } 2016\end{array}$ & 5 & 4 & 11 \\
\hline 5 & $\begin{array}{l}\text { Da Silva } \\
\text { Freitas } \\
\text { Junior J.C. }\end{array}$ & $\begin{array}{l}\text { Federal } \\
\text { University of } \\
\text { Rio Grande } \\
\text { do Sul }\end{array}$ & Brazil & 4 & 2016 & $\begin{array}{l}\text { Digital capabilities as driver } \\
\text { to digital business } \\
\text { performance }\end{array}$ & $\begin{array}{l}\text { AMCIS 2016: Surfing } \\
\text { the IT Innovation } \\
\text { Wave - 22nd Americas } \\
\text { Conference on } \\
\text { Information Systems }\end{array}$ & 3 & 4 & 4 \\
\hline 6 & $\begin{array}{l}\text { Saint-Nom } \\
\text { R. }\end{array}$ & $\begin{array}{l}\text { Buenos Aires } \\
\text { Institute of } \\
\text { Technology }\end{array}$ & Argentina & 2 & 2003 & $\begin{array}{l}\text { Switched capacitors: A bridge } \\
\text { between analog and digital SP }\end{array}$ & $\begin{array}{l}\text { ICASSP, IEEE } \\
\text { International } \\
\text { Conference on } \\
\text { Acoustics, Speech and } \\
\text { Signal Processing - } \\
\text { Proceedings }\end{array}$ & 119 & 3 & 3 \\
\hline 7 & $\begin{array}{l}\text { Tumelero } \\
\text { C. }\end{array}$ & $\begin{array}{l}\text { University of } \\
\text { São Paulo }\end{array}$ & Brazil & 3 & 2019 & $\begin{array}{l}\text { Cooperation in } \mathrm{R} \& \mathrm{D} \text { and } \\
\text { eco-innovations: The role in } \\
\text { companies' socioeconomic } \\
\text { performance }\end{array}$ & $\begin{array}{l}\text { Journal of Cleaner } \\
\text { Production }\end{array}$ & 132 & 2 & 3 \\
\hline
\end{tabular}


8 Frank A.G. Universidade Brazil

Federal do

Rio Grande

do Sul

9 Arts K. Wageningen Netherlands 6

University

and Research

10 Ebert C. Implementation patterns in Production Economics

manufacturing companies

2018 Online and offline Sustainability representations of biocultural (Switzerland) diversity: A political ecology perspective on nature-based tourism and indigenous communities in the Brazilian Pantanal

2018 Digital Transformation IEEE Software

Consulting Services

Source: Author's based on Scopus (2019) SCImago (2019) and Google Scholar (GS) (2019). 


\subsection{Research key-terms network}

Figure 7 presents the co-occurrence network based on documents' key-terms. DT was most associated with terms such as "Industry 4.0"; "smart manufacturing" and "Internet of Things".
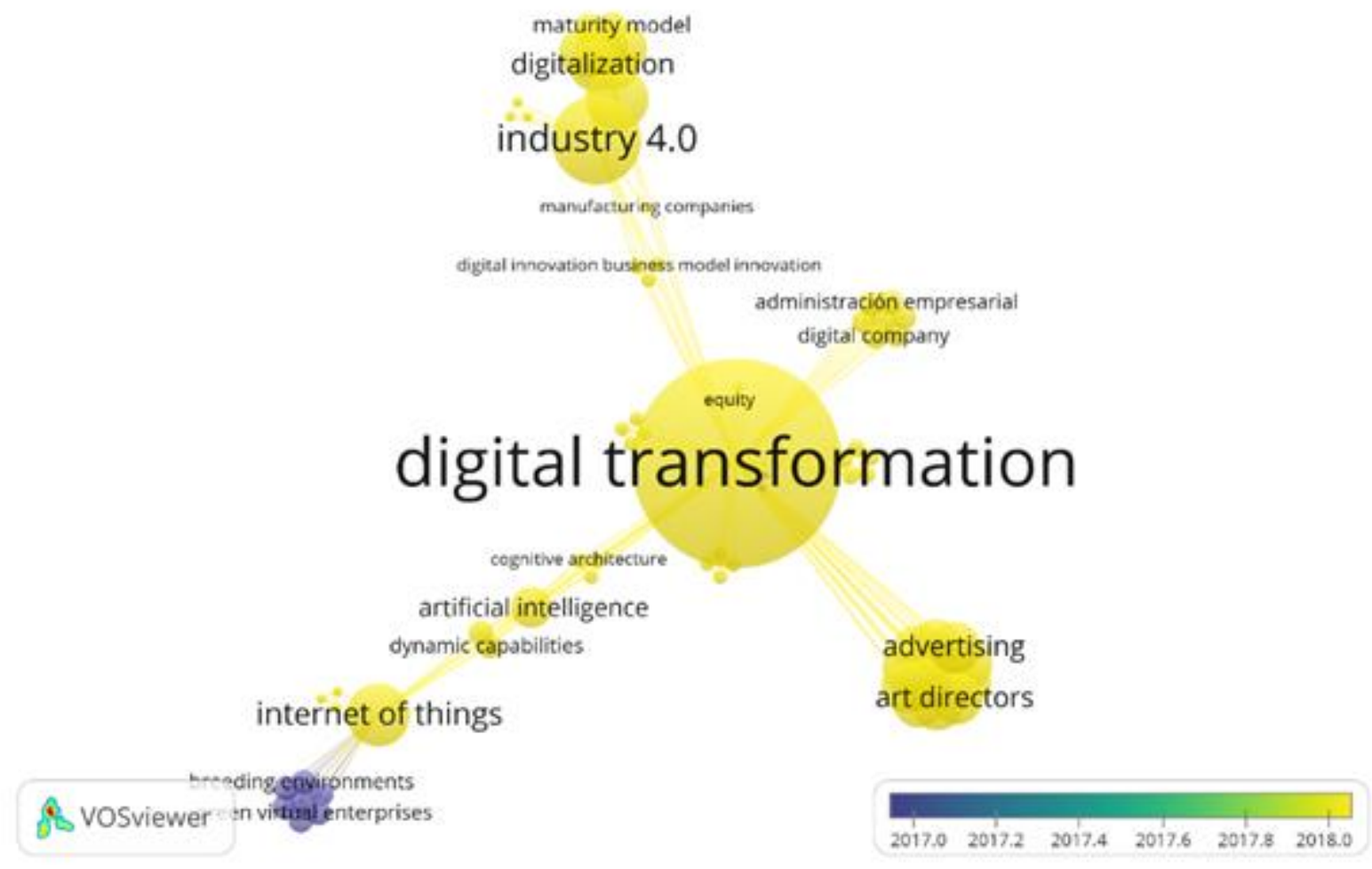

Figure 7. Keywords co-occurrence network. Source: VOSviewer based on Scopus (2019).

\section{Discussion}

DT research network in LATAM is internally disconnected. Researchers are publishing with scholars within the same country and foreign countries, but not with researcher within LATAM. Degree's properties aside, the network resembles more like a European network. Nodes such as United States, Netherlands, Spain, Australia and India may serve as bridges that could bring together authors from LATAM. Brazil is the node with the highest degree, which is also reflected by its elevated participation as the home country of the first authors in the $40 \%$ of the sample. México is the most diverse node, with co-authors from Europe, Asia, and Oceania, followed by Brazil, connected only to European and North American countries. Therefore, geographic factors seems to have low impact in scientific collaboration (Gossart \& Özman, 2009; Ponds et al., 2007). It is feasible to argue that this European-influenced network is due to the dawn of Industry 4.0 and DT related research in Germany (Lasi, et al., 2014; Muhuri et al., 2019). Furthermore, the European Commission has developed an industrial policy framework on Industry 4.0 and DT to build on its strengths in areas such as IoT, Big Data, $3 \mathrm{D}$ printing, and so forth.

Regarding the institutional network, the majority of nodes are grouped in pairs instead of communities (three or more nodes linked). Universities and research centers are in the top ten most influential nodes. The private 
sector is marginally present with firms such as Boeing, Vector Consulting Services and Renault. Six communities could be identified. LATAM institutions are serving as highly connected nodes within these communities, such as Federal University of Rio Grande do Sul, Instituto Tecnológico de Monterrey, and Federal University of Mato Grosso as evidenced in their betweenness and closeness properties. In the case of the Instituto Tecnológico de Monterrey, there is a bachelor program in Digital Transformation Engineering, one of a kind in LATAM to the best knowledge. The offering of this program demands intellectual (human, social, and structural) capital for its success, definitely, research and international collaboration on DT (Instituto Tecnológico de Monterrey, n.d.). LATAM institutions could direct their efforts in linking with those institutions to increase the network's connectivity.

The mean number of authors is increasing yet behind the global dynamic of "team science" (i.e., the production of knowledge is now dominated by teams). Over the past 45 years, the average number of authors per paper has increased from 1.9 to 3.5 (Wuchty et al., 2007). In this study, the mean number of authors also has increasing from 2 to 3 between 2016 and 2018. The overall mean was 2.7. In specific subjects, the gap between this study and global trends is increasing. In computer science research during 1960-2009, the annual number of coauthors for average author increased from 1 to 4 . In the case of uninterrupted, continuous presence (UCP) authors (Ioannidis et al., 2014) that number increased from 2 to 11 (Wu et al., 2016).

In the case of the co-authorship network in management and organizational studies, the mean degree is 2.86 and the density 0.0002 (Acedo et al., 2006). Compared to the findings in this study, both countries and institutional networks' density are much higher with 0.07 and 0.039 scores respectively, while the mean degree scores of 1.7 and 1.2 in countries and institutions network are way behind that threshold.

Several strategies could be outlined to increase the density of co-authorship to increase citations, nevertheless, this is not a rule of thumb for every field nor region. Highly cited papers exhibit several common characteristics, such as a large number of co-authors, international collaboration, presence in high impact journals (top 10\%) and receive citations from global scholars (Aksnes, 2003). In addition, Persson et al. (2004) found a significant relationship between co-authorship density and citations. In consequence, is the co-authorship increasing an assured strategy for citation growing in DT research in LATAM where 65\% of the papers have no citations?

The author of this study argues the progressive integration of LATAM authors to international networks would help to advance towards the path to a boarder acknowledgment of the LATAM research in DT. In the subject of innovation in management research in LATAM, there was not correlation between authors per paper and citations, otherwise, papers led by non-LATAM authors were significantly more cited and published in journals with higher h-index (Cortés-Sánchez, 2018). In scientific publishing, this effect has started to be acknowledged as "The chaperone effect": the role played by experience in publishing within specific scientific journals on the paths toward acquiring the necessary experience and expertise and on the skills required to publish in prestigious venues (Sekara et al., 2018, p. 12603). This can be illustrated also by two examples. First, the outlier document. The article entitled: "Realizing strategic value through center-edge digital transformation in consumer-centric industries" is the most cited document with 18 citations in Google Scholar. It was authored by Gray, P. (2013) then affiliated to Claremont Graduate University (United States), and three additional authors, two from United States also (University of Southern California and an independent consultant) and one from University of Brasilia (Brazil). As noted, the co-authorship was led and was mostly integrated by authors from United States. Second, the earlier yet completely from LATAM document. Lasi et al. (2014) was the first and is the most cited documents on Industry 4.0 and DT (Muhuri et al., 2019). Yet the paper authored by Saint-Nom and Jacoby (2004) on digital transformations in signal processing was published ten years before Lasi's et al. Regardless it was published in the IEEE International Symposium on Circuits and Systems with an h-index of 62 (2.2 was the journal's h-index mean) it has only 3 citations in Scopus and 4 in Google Scholar. The caveat: 
both authors were affiliated to the Buenos Aires Institute of Technology (Argentina). It lacked from international (leading) co-authors.

The most consolidated research agenda on DT orbits around "Industry 4.0" and "smart manufacturing". Most of the research in this line, has to do with DT models' implementation patterns identification (Frank et al., 2019) and evaluation (Ramos et al., 2018) in both manufacturing and services (Frank et al., 2019) sectors and SMEs (Mittal et al., 2018). The following most consolidated topic was "Internet of Things" (IoT). Topics being study in this line are focused on the relationship between smart cities and the IoT in low density regions and how cities use innovative solutions that optimize citizens' daily lives (Lopes \& Guarda, 2019) and the introduction of new concepts such as Green Sensing Virtual Enterprises(i.e., goal-oriented networks connected by short-term alliance of green enterprises with sensing capabilities supported by computer systems) (Romero \& Noran, 2017).

The most productive leading authors were Ebert, C., Álvarez-Flores E.P., and Da Silva Freitas J.C., each one with two documents. The case of Ebert shall be highlighted as he is affiliated to Vector Consulting Services (India) and has published 121 documents cited 1883 times (h-index 24). Since the authorship composition was not dominated by private firm affiliations, it is worthy to notice that an author from the private sector has such productivity and impact in DT research. A closer look at the authors' network, allows to identify an enriching and diverse international intellectual community, in particular cases although. Authors such as Romero, D. at the Instituto Tecnológico de Monterrey, has participated in research with authors from IEEE TEMS (Netherlands), Leiden University (Netherlands), Griffith University (Australia) and West Virginia University (United States).

Finally, a reduced $11 \%$ of the documents have golden open access (journal's digital content free for readers) and two publishers involved in the so-called oligopoly of scholarly communication (Larivière et al., 2015) own $25 \%$ of the publisher's market (i.e., Springer and Elsevier). Despite the virtues of the DT to convert knowledge and information from paper into zeroes and ones and make it available around the world through broadband or satellite, there is reduced access to DT research due to editorials' pay-wall restrictions.

\section{Conclusion}

The research on DT in LATAM over the past 15 years has been developing a growing and geographically diverse intellectual community, yet fragmented and mostly originated from computer sciences. Brazil and Mexico and institutions such as the Federal University of Rio Grande do Sul and Instituto Tecnológico de Monterrey, are key actors in these communities. The presence of authors affiliated to private firms is reduced but considerably influencing at a global scale. Most LATAM countries are missing from the intellectual production and network integration as the time is passing by. The networks here presented are crucial to identifying key actors in DT research and to look after collective research agendas along with influencing nodes. Consolidated topics such as "Industry 4.0", "smart manufacturing" and "IoT" seems to have more traction and reconnaissance in LATAM. Despite that topics such as "Big Data" and "Artificial Intelligence" are crucial components of the industrial policy at the European Commission, their state in LATAM is still embryonic. Efforts could be made at the national-institutional level to allocate resources in these topics. DT attributes such as "the omnipresence of digital content within the reach of your fingertips" was not found due to publishing restriction (pay-wall). This suggest that research on DT also should advance along with the open access agenda.

Future research could design and test strategies for increasing DT research impact: should scholars from LATAM research along with local communities? Or, before that, they should join international research teams led by DT experts and then seek independence using the skills acquired in the process? Future research also 
could use different bibliometric platforms, such as Google Scholar or Microsoft Academic, considering the citation records differences noticed here. Finally, DT research in LATAM shows considerable advances for the regional context and has the sufficient intellectual substrate to progressively close the gaps with the international pace.

\section{Contribution}

This study was conducted by the lead-author himself.

\section{Disclosure statement}

The author has no conflict of interest to declare.

\section{Funding}

This study was not funded.

\section{Acknowledgments}

The author would like to thank to Universidad del Rosario's School of Management, and Dr. Julia Jensen for her valuable proofreading assistance.

\section{Agradecimientos}

El autor agradece a la Escuela de Administración de la Universidad del Rosario, y a la Dra. Julia Jensen por su valiosa asistencia en la corrección de estilo de este manuscrito.

\section{References}

Acedo, F. J.; Barroso, C.; Casanueva, C.; Galán, J. L. (2006). Co-Authorship in Management and Organizational Studies: An Empirical and Network Analysis*. Journal of Management Studies, 43 (5), 957-983. https://doi.org/10.1111/j.1467-6486.2006.00625.x

Ahrens, V. (2012). Inflation of industrial revolution. Productivity Management, 17 (5), 30-31.

Aksnes, D. W. (2003). Characteristics of highly cited papers. Research Evaluation, 12 (3), 159-170. https://doi.org/10.3152/147154403781776645

Cortés-Sánchez, J. D. (2018). Innovation in Latin America through the lens of bibliometrics - Noiseless, crammed and fading away. https://doi.org/10.31235/osf.io/7rqkt

Frank, A. G.; Dalenogare, L. S.; Ayala, N. F. (2019). Industry 4.0 technologies: Implementation patterns in manufacturing companies. International Journal of Production Economics, 210, 15-26. https://doi.org/10.1016/j.ijpe.2019.01.004

Frank, A. G.; Mendes, G. H. S.; Ayala, N. F.; Ghezzi, A. (2019). Servitization and Industry 4.0 convergence in the digital transformation of product firms: A business model innovation perspective. Article in Press. https://doi.org/10.1016/j.techfore.2019.01.014

Glänzel, W.; Schubert, A. (2005). Analysing Scientific Networks Through Co-Authorship. In H. F. Moed, W. Glänzel, \& U. Schmoch (Eds.), Handbook of Quantitative Science and Technology Research: The Use of Publication and Patent Statistics in Studies of ST Systems (pp. 257-276). Dordrecht: Springer Netherlands. https://doi.org/10.1007/1-4020-2755-9_12 
Gossart, C.; Özman, M. (2009). Co-authorship networks in social sciences: The case of Turkey. Scientometrics, 78 (2), 323-345. https://doi.org/10.1007/s11192-007-1963-x

Gray, P.; El Sawy, O. A.; Asper, G.; Thordarson, M. (2013). Realizing strategic value through center-edge digital transformation in consumer-centric industries. MIS Quarterly Executive, 12 (1), 1-17.

Hirsch, J. E. (2005). An index to quantify an individual's scientific research output. Proceedings of the National Academy of Sciences of the United States of America, 102 (46), 16569-16572. https://doi.org/10.1073/pnas.0507655102

Iacobucci, D.; McBride, R.; Popovich, D.; Rouziou, M. (2017). In Social Network Analysis, Which Centrality Index Should I Use?: Theoretical Differences and Empirical Similarities among Top Centralities. Journal of Methods and Measurement in the Social Sciences, 8 (2), 72-99.

Ioannidis, J. P. A.; Boyack, K. W.; Klavans, R. (2014). Estimates of the Continuously Publishing Core in the Scientific Workforce. PLOS ONE, 9 (7), e101698. https://doi.org/10.1371/journal.pone.0101698

Instituto Tecnológico de Monterrey (n.d.). Ingeniero en Transformación Digital de Negocios. Retrieved from: https://admision.itesm.mx/es/ingenieria-computacion/itd

ITU. (2018). Accelerating Digital Transformation - Good practices for developing, driving and accelerating ICT centric innovation ecosystems in Europe. Geneva: ITU.

Larivière, V.; Haustein, S.; Mongeon, P. (2015). The Oligopoly of Academic Publishers in the Digital Era. PLOS ONE, 10 (6), e0127502. https://doi.org/10.1371/journal.pone.0127502

Lasi, H.; Fettke, P.; Kemper, H.-G.; Feld, T.; Hoffmann, M. (2014). Industry 4.0. Business \& Information Systems Engineering, 6 (4), 239-242. https://doi.org/10.1007/s12599-014-0334-4

Lee, J.; Bagheri, B.; Kao, H.-A. (2015). A Cyber-Physical Systems architecture for Industry 4.0-based manufacturing systems. Manufacturing $\quad$ Letters, $\quad 3, \quad 18-23$. https://doi.org/10.1016/j.mfglet.2014.12.001

Lopes, I. M.; Guarda, T. (2019). The relationship between smart cities and the internet of things in low density regions (Vol. 850). In: Antipova T., Rocha A. (eds) Digital Science. DSIC18 2018. Advances in Intelligent Systems and Computing, vol 850. Springer, Cham https://doi.org/10.1007/978-3-03002351-5_42

Martín-Martín, A.; Orduna-Malea, E.; Thelwall, M.; Delgado López-Cózar, E. (2018). Google Scholar, Web of Science, and Scopus: A systematic comparison of citations in 252 subject categories. Journal of Informetrics, 12 (4), 1160-1177. https://doi.org/10.1016/j.joi.2018.09.002

Mittal, S.; Romero, D.; Wuest, T. (2018). Towards a smart manufacturing maturity model for SMEs (SM3E) (Vol. 536). Conference: APMS - Production Management for Data-driven, Intelligent, Collaborative, and Sustainable ManufacturingAt: Seoul, KoreaVolume: I. Moon et al. (Eds.), IFIP, AICT 536, Part II, Springer, pp. 155-163 https://doi.org/10.1007/978-3-319-99707-0_20

Muhuri, P. K.; Shukla, A. K.; Abraham, A. (2019). Industry 4.0: A bibliometric analysis and detailed overview. Engineering Applications of Artificial Intelligence, 78, 218-235. https://doi.org/10.1016/j.engappai.2018.11.007 
Opsahl, T.; Agneessens, F.; Skvoretz, J. (2010). Node centrality in weighted networks: Generalizing degree and shortest paths. Social Networks, 32 (3), 245-251. https://doi.org/10.1016/j.socnet.2010.03.006

Persson, O.; Glänzel, W.; Danell, R. (2004). Inflationary bibliometric values: The role of scientific collaboration and the need for relative indicators in evaluative studies. Scientometrics, 60 (3), 421-432. https://doi.org/10.1023/B:SCIE.0000034384.35498.7d

Ponds, R.; Oort, F. V.; Frenken, K. (2007). The geographical and institutional proximity of research collaboration*. Papers in Regional Science, 86 (3), 423-443. https://doi.org/10.1111/j.14355957.2007.00126.x

Ramos, L.; Loures, E.; Deschamps, F.; Giesel, E.; Savaris, E. (2018). Systems evaluation methodology to attend the digital projects requirements for industry 4.0 (Vol. 7, pp. 3-12). Presented at the Advances in Transdisciplinary Engineering. https://doi.org/10.3233/978-1-61499-898-3-3

Romero, D.; Noran, O. (2017). Towards Green Sensing Virtual Enterprises: Interconnected Sensing Enterprises, Intelligent Assets and Smart Products in the Cyber-Physical Circular Economy. IFACPapersOnLine, 50 (1), 11719-11724. https://doi.org/10.1016/j.ifacol.2017.08.1944

Ruhnau, B. (2000). Eigenvector-centrality - a node-centrality? Social Networks, 22 (4), 357-365. https://doi.org/10.1016/S0378-8733(00)00031-9

Saint-Nom, R.; Jacoby, D. (2004). Switched capacitors: A bridge between analog and digital SP (Vol. 1, pp. I841-I844). Presented at the Proceedings - IEEE International Symposium on Circuits and Systems. Retrieved from https://goo.gl/CQb5og

Scopus. (2018). Search. Retrieved from https://www.scopus.com/

Scott, J. (1988). Social Network Analysis. Sociology, 22 (1), 109-127. https://doi.org/10.1177/0038038588022001007

Sekara, V.; Deville, P.; Ahnert, S. E.; Barabási, A.-L.; Sinatra, R.; Lehmann, S. (2018). The chaperone effect in scientific publishing. Proceedings of the National Academy of Sciences, 115 (50), 12603-12607. https://doi.org/10.1073/pnas.1800471115

Stokalski, B.; Kaminski, B. (2016). All the world's a sound stage: The digital transformation journey in the era of Hollywood economics. Cutter IT Journal, 29 (8-9). Retrieved from https://www.scopus.com/inward/record.uri?eid=2-s2.084990239605 partnerID=40md5=d1c96d819f5542f5a399e 3321f154e30

Wu, Y.; Venkatramanan, S.; Chiu, D. M. (2016). Research collaboration and topic trends in Computer Science based on top active authors. PeerJ Computer Science, 2, e41. https://doi.org/10.7717/peerj-cs.41

Wuchty, S.; Jones, B. F.; Uzzi, B. (2007). The increasing dominance of teams in production of knowledge. Science, 316(5827), 1036-1039. https://doi.org/10.1126/science.1136099

Zupic, I.; Čater, T. (2015). Bibliometric Methods in Management and Organization. Organizational Research Methods, 18 (3), 429-472. https://doi.org/10.1177/1094428114562629 
